that the College's 'Overseas Doctors Training Scheme' will be helpful in this respect.

Effective action on 'Achieving a Balance' depends very much on good communication between the College and all its members. In particular we have done our best to brief Regional Advisers and Psychiatric Tutors and they in their turn, together with our College Assessors, have told us about the state of consultant appointments and the adequacy or inadequacy of the supply of applicants for consultant posts. Up to date and accurate information on these matters will be essential for planning future developments.

\title{
In conversation with Felix Post: Part II
}

This is the second part of Brian Barraclough's interview with Dr Felix Post. Part I appeared in the February Psychiatric Bulletin.

BB Now, I would like to turn to the development of your psychogeriatric interests. You described how Lewis suggested you take up psychogeriatrics and gave you some beds at the Bethlem for that purpose.

FP One ward at first. He had a tremendous standup fight with the Matron, Miss Robinson, who was against the beautiful recently private Bethlem Hospital being occupied by these nasty old people. But Lewis won. The Matron later became a most fervent admirer of the Unit, and delighted in it.

At first I had just a few beds in a general ward. But it developed and by about 1950-51 the whole place was more or less devoted to people over 60 . I was fortunate that one of my first registrars was so interested in working with the aged. That was David Kay. He stayed a year, instead of six months.

BB He went on to Graylingwell Hospital?

FP Yes. He was passed from me to Roth, and never looked back. David co-operated in a study of our observation ward patients where we tried to predict the outcome from the diagnosis. There was a serious disadvantage with this kind of work at the Bethlem Unit which applied to the Maudsley as well. Both were hospitals for patients likely to recover. Anybody who had a chronic mental illness had to go to one of the area mental hospitals. They couldn't stay at the Bethlem or the Maudsley. There was no exact time limit but there were questions asked if the patient stayed too long.

That, of course, in psychogeriatrics limits you entirely to the affective and neurotic illnesses. If you have dementias you have to offer long-term care. Each time we did have patients with organic mental syndromes we hoped they would improve or that other arrangements would be made by the relatives. But again and again they would occupy a bed for months and months before the local hospital would graciously accept them. Therefore we were restricted in the study of the most important psycho-geriatric condition, dementia. This problem was only more or less cured in the late 1960 s and early 1970 s when beds nominally under the jurisdiction of the joint hospital in the area hospital became available to long-stay patients from the catchment area of the unit. It is a great improvement which has helped my successor to develop more interest in the dementias than I could.

BB What were your aims when you began?

FP All one knew about mental illness in the aged in 1947 was that their depressions tended to be more severe, more chronic, and recur often. Paranoid illnesses? We were not sure what they were all about. I soon realised that I couldn't say anything useful about these conditions without following them up in sufficient 
numbers to draw conclusions about the course of the disease. That had not been done before, and that was what I did, up to a point.

BB Did you develop these aims on your own?

FP Yes. I wasn't put up to it. For example David Kay and I confirmed there were clear distinctions between organic and affective disorders in the short term. Then there was the question, not so obvious, whether or not a high proportion of the depressive subjects demented.

The study that Roth, Kay and Hopkins carried out at Graylingwell was also a followup study. I was doing mine at the same time but theirs was a bit different in terms of the follow-up period which varied a great deal, a minimum of 18 months. I decided that it was necessary to follow up all patients for the same period of time. That of course came out in 1962 based on patients who were in the hospital in the 1950s.

BB What did you find?

FP The main point was that, compared with known statistics about the prevalence of dementing disorders in old age, there was no evidence that depressive subjects without brain symptoms subsequently developed them. That corroborated the findings of Roth and his colleagues which came out around the same time.

Cerebral organic symptoms occurring with depression were of prognostic significance only when clear cut and definite. Dubious dementia, memory disturbance when patients couldn't do this or that, a little facial alteration, the "minimal signs" of organic involvement, did not predict dementia. Sometimes I suppose they did, but very rarely in any sense that would make one take notice of dubious psycho-organic signs. On the other hand were patients who did have some brain changes. Usually they would not be of senile dementia but more of what was then called arteriosclerotic dementia; then the immediate outcome for the depression may be quite good, but the ultimate outlook, even in terms of the depression let alone the brain, are far less good. That was the most clear thing that came out. Lots of other things came out, for instance, a very high proportion of depressives had previous neurotic symptoms; then I looked at various possible sub-types of depression and of depressions which had first manifested themselves in the senile period, compared them in various ways but really did not find that any of these "Aunt Sallys" of subtypes of depressive illnesses in the elderly stood up to investigation.
The next question $I$ investigated were the differences between depressions that start late in life and those that began early in life and persist into late life.

There is a lowering of arousal, even in agitated depression, as measured by EEG changes during sleep or by sedation thresholds with barbiturates. There is a similar lowering of arousal with dementia. The idea therefore was that patients with late onset depression and minimal brain changes, the result of ageing, will have a lower arousal level predisposing them to depression. In contrast, those with early onset depression would not have age-related minimal brain changes, and therefore normal arousal. We did show that this was so in one group but couldn't replicate the finding, so the whole thing is inconclusive.

The subject has now been taken up by Levy and Jacoby, using computerised tomography to measure brain changes instead of arousal levels. They have found that patients who develop depressions late in life for the first time do have more brain changes, more severe brain changes and a shorter duration of life, all at a statistically acceptable level, but not too convincing all the same. It is unsolved.

The notion that elderly patients are more severely depressed is wrong. That's been taken over from previous accounts. In fact the later depressions are less severe, but longer lasting and more frequently recurring, with a higher death rate. Elaine Murphy found this in a recent study. Incidentally the main findings on prognosis of depression were confirmed by me and again quite recently by Baldwin and Jolley. So apart from the biological mechanisms the clinical course for the elderly depressives is now a clearer picture.

The other topic I worked on was rather more difficult because there were fewer patients, some had to be collected retrospectively. These paranoid delusional states were by the course of the disorder and response to treatment not secondary to affective disorders. Some of them were included because one was not sure at the time about the association of paranoid symptoms with any cerebral organic condition.

BB Had paranoid states been much studied before?

FP There was the paper by Roth and Morissey. Roth described this group, in an observation far more innovating than the distinction he made between affective and organic disorders. He described a small group at Graylingwell who had paranoid symptoms of the kind long called paraphrenia-hallucinations and 
delusions in an otherwise well maintained personality, occurring in later life. He described this group too and went into speculations about whether this was a late kind of schizophrenia. Kay had followed such patients in this country and in Sweden. Late paraphrenia was a well described disorder.

I started a double blind trial to compare paraphrenic patients treated at the Bethlem and Maudsley Hospitals before and after the introduction of phenothiazines. But I had to have eye surgery and I could not get back for some months. By the time I came back the response of paraphrenic patients to phenothiazines was so undoubted that it would have been unethical to leave a large number untreated as a control. It wouldn't have been unethical just for two or three weeks, as one does in depressions, but it would have been for the six weeks to two months required here.

The study showed the results of treatment and related the symptomatology to the previous personality and to outcome. There are three ways in which paranoid symptomatology shows itself in old age. One is by paranoid ideas or delusions or hallucinations in a very narrow field, like thinking that coal is being stolen or that people talk about you downstairs. Then there is one with much more widely spread signs but not of "first rank" in the sense that Schneider uses the term. Then thirdly there are those with classical schizophrenic symptoms. These three types remain stable and respond equally to phenothiazines. Whether they are three separate conditions is unknown. Others have confirmed these subgroups exist.

Another interesting subject were paranoid disorders which developed in the course of a cerebral organic condition, a stroke or senile dementia. So one has paranoid symptomology in three forms occurring in various clinical settings including depressions, or in pure culture. But whether this pure culture condition is a separate illness or a late form of schizophrenia is unknown. Recent investigations have described a genetic marker present in the younger paranoid schizophrenic which is not present in paraphrenics. This suggests paraphrenia to be a distinct condition.

BB You were employed as an NHS consultant?

FP That's right.

BB In general it's not possible for NHS consultants to do as much research as you.

FP Oh I don't know, I had contemporaries who were NHS who did. Think of Edward Hare. When I was appointed it was said that physicians were to teach and to do research. So whenever any duties were distributed I would say I have to have time for research. But I never took study leave or anything like that.

BB Edward Hare said he took two days a week, promised by Aubrey Lewis.

FP Actually I was allowed to go, for a time, one day a week to Oxford, because one of the geriatricians there was interested to see whether dementia could be improved by suitable stimulation with occupational and social therapies. They had a good community therapist and a good psychologist who were interested in disorders of old age. I was lent as a sort of organiser to lead them. I went once a week for about a year to do this work. So in a sense I suppose I did have study leave for about a year.

The aim was to identify the dements who were likely to survive more than six months. We did this, and then ran various occupational and social programmes to stimulate them, with the psychologist monitoring the outcome. And what it showed, not surprisingly, was that whatever you did raised the level of measured purposeful activity. But as soon as you left off, they could not get going again on their own. This was really disappointing to my geriatrician colleague.

BB I meant did you have a regular one or two days a week as part of the job?

FP No, there was only that one occasion. But otherwise, you see, all the work I did was on my own patients. They were looked after by the registrars, but I saw them twice, three times, or more often during their hospital stay in the manner you experienced. I conducted the follow-ups even when there wasn't any special research.

BB Where do you think your interest in research came from? Was it the influence of Stengel or Slater perhaps that induced you to think curiously?

FP What fascinated me about psychiatry was the human mind. Why people develop mental diseases, that would be a big area to work on, I thought. As soon as I was in contact with patients I began to want to find out a little bit more. At one time I was interested in anorexia nervosa and published a paper on it. But then Denis Leigh took this subject over. I was also interested in the type of patient who has an unduly high prevalence of relatives, not only blood relatives, who are affected by some psychiatric condition. We did quite a nice investigation and found that chronic neurotic patients were especially prone to have other neurotic people in their social networks. A nice piece of work I thought at the time. I wanted to 
go on with it but I couldn't get a grant. I suppose it was quite fair that I shouldn't extend into this area when other people were beginning to take it up. Besides I was getting more into my studies of the elderly.

At that time in the Maudsley I did not have competition, nobody else was doing research on the elderly. It was natural, I think, to try to find ways of predicting which one of these depressive patients was going to do well, which one was going to do badly. It's an obvious goal. So I concentrated on the older patient and realised that there is no point just following them to the last ECT and sending them out of the hospital and saying they are cured, but to look upon an episode of psychiatric illness as a phase in a life. There is no point just looking at the illness. You have to look at the life, not only the life before, that you can do as history, but the life after, which you have to do by follow up. I don't think anybody put me up to it you know. It came to me as a natural part of wanting to help patients. You really want to see what good you are doing, what contribution you are making to the life of these people.

BB What I am driving at is this. When somebody takes up scientific work then usually they have come from a scientific background or somebody has taught them to look at things in a scientific way. Neither applies to you. Your family were not scientific and you had no scientific training.

FP I don't think I agree. I am at present reading biographies of scientists. Many do not come from scientific backgrounds. They are highly gifted people, who get into a certain type of work at an early age. I am not comparing myself with them of course. At a very early age they want to find things out. Some have published papers at the age of 15 or 16 . Take Faraday for instance. He was almost entirely self taught in chemistry, physics and electricity, no background at all. He was Humphrey Davy's lab assistant.

BB I think he had Davy as a teacher and model.

FP Yes, in a way Davy was his teacher. But I believe the idea of investigating was a natural development. You learn all there is to learn, and then you want to go on from that. That's how it was with me.

BB Would you like to say something about the contentious subject of leucotomy?

FP Aubrey Lewis was involved with the neurosurgeons in evaluating leucotomy, a very ambitious project. They were to use three different operations in a properly randomised way. Linford Rees, Schurr and Falconer wanted to assess, retrospectively, the results of their work. The trial had ground to a halt. I don't know why. I think it was because of my expertise, as it were, in follow-up studies that they asked me to collaborate. We got a research grant for a social worker and followed up nearly a hundred people, who had had one of the operations. We devised scales with which to score their case notes, retrospectively, their responses to interviews, and their relatives assessments. This was to measure their post-operative progress to find if certain types of surgery had done better than others. That was my only investigation.

BB Was the study intended to evaluate whether leucotomy was effective or whether types of leucotomy differed in their outcome?

FP The original study was large and well planned and its purpose was to compare the clinical effect of different operations.

BB There was not a control group?

FP No. That was ethically not possible.

BB What is your view of leucotomy now?

FP The opportunities for it, the need for it are fewer and fewer. In its time leucotomy did improve the symptoms which can now largely be controlled by drugs. But the real problems which make schizophrenic people, for instance, socially so often incompetent are not reached by drugs or by leucotomy; in fact some are made worse by surgery. For depression at that time ECT was the only treatment as tricyclics had not been devised. There were patients who did not improve with many ECTs or who, if they did, persistently relapsed. They might be kept going by maintenance ECT, or so it was called. There weren't any drugs, no lithium or anything, and so in those days leucotomy was an important treatment. Now there are far fewer patients likely to need it.

In the July 1987 edition of the Journal people from the Brook Hospital report there are still patients who cannot be managed by non-surgical means and who respond to a tractotomy. This is a much more limited operation than the one which my patients had. In the last few years of my consultantship I no longer referred any patients for surgery at all. Other treatments were satisfactory, or if patients did not respond and became chronic they would refuse to give consent to the operation. Or they were physically unfit. We did show in an earlier study that patients who were physically not fit, not just in their brains, did not do so well after a leucotomy. But this has nothing to do with the difficulties now placed in the way of the would be leucotomists to ply their trade. 
BB You are convinced that it is an effective treatment?

FP It is an effective treatment in certain patients, who have not responded to other ways. Yes, I am quite convinced of that.

BB But how do you handle a critic who says where is the evidence?

FP This is in the various publications.

BB But the critic says there has been no adequate controlled trial?

FP You can't do a controlled trial of leucotomy. The controlled trial is useful to compare the value of two different drugs or two different treatments, a new against an old. But when the patient has had all the available treatment, and you give a treatment which cures, or improves, then the presumption must be it is that treatment which caused the change. The probability of the change being due to chance is remote; it can happen, but is highly improbable. I think that is good enough really.

BB Do you? Well I do too. But there are others who do not. They say, for example, that the longer the illness goes on the more likely it is to reach a point of natural remission.

FP Well quite, that's fine, excellent. But supposing the leucotomy shortens the natural length of the illness by two months, three months, six months, a year, two years or whatever, the longer the better you see, it is still a valuable thing. I have never been really depressed. To be depressed must be absolute hell, and to be let out of that hell, and it usually is hell for patients who have a leucotomy, is really worth doing.

BB Another argument is that it is not the cut in the brain but the so-called "aura of neurosurgery" which effects the change.

FP If patients are that suggestible I am surprised they have not already responded to other treatments.

My main pleasure at the Maudsley was the wonderful, the excellent junior staff that I had. There were, it is true, very occasionally difficult or impossible, or even incapable people. Very, very rare. As a rule one worked with people who were tremendously interested, very capable. I suppose about six junior doctors went through my hands annually, three changing every six months. So there are lots of people who came through and so I can't give you all their names, unless you want me to. There is a phrase "In teaching we learn". That's what I have done, because I like teaching and I have been told by many people that I was good at it.

BB I agree with that.
FP I enjoyed having the resonance of capable and interesting people, who put their life's interest into their work. That was a great spur, and what I miss now.

BB Would you like to reminisce on some of your registrars?

FP Well, for instance, I always remembered you.

BB I regard myself as one of the worst students you ever had.

FP No, not at all.

It started with Shepherd. When I took over Guttman's beds Shepherd was the registrar. The poor man must have been very disappointed and sad because really I had no business to teach anybody. He was very good, very pleasant, obviously an able man. The next one was Storr. Isaac Marks made a mark, if you will pardon the pun, by being the only registrar who ever made me come to the Villa on a Saturday afternoon to help him with a patient. And that was a good mark in my opinion, an excellent mark. Another who stands out is Kreitman. Yes, he was very good indeed. He was the only registrar ever to ask me at the end of his term in office a question, "What do you think of me, my work, my abilities?". He was the only one, isn't that amazing.

BB What did you tell him?

FP I told him I had a very high opinion of him.

There were lots of others. Among them was Gerald Russell, he was in geriatrics. And there was Kendell, Bob Kendell; many very, very wonderful people to have, really a great pleasure and joy. David Kay I mentioned already, because he collaborated with me a great deal, as did Bob Cawley as a fellow investigator. And then of course from the psychogeriatric point of view, there are perhaps two people who were most important. Tom Arie, one of the leaders of the subject now, and Raymond Levy, the first Professor in the Department of the Psychiatry of Old Age.

BB What do you do now, clinically?

FP Nothing. I am invited to meetings and conferences. I am going again to Canada in the autumn to be a visiting Professor for the second time, otherwise I don't do any clinical work.

BB Writing?

FP Writing and not being published. In the first few years of my retirement, up until a year or two ago in fact, I had always something to write, chapters on this and that. I did them because I did not want to say no. But it got a bit boring. Then I also read, for my own entertainment, on the psychiatric aspects of modern biographies of famous people. I found it interesting. To my surprise there was a lot of 
psychiatric stuff there. Not interpretations of their novels, plays and so on. They do not fully explain the problems and complexes that the writer had. But simply accounts of their lives, what they did, and what illnesses they had, what people wrote about them, how much they drank, their love affairs, their marital lives.

I decided to investigate these biographies for factual evidence of psychopathology. There is the old idea, now exploded quite satisfactorily, that genius and madness go together. I first took a group who I thought were most likely to be earth-bound, and normal. These were mainly recent dramatists and novelists, people who lived in the past 150 years. I did 55 of those. I found that only one or two had become psychotic. But I did find they had a tremendously high incidence of minor psychiatric illnesses, some disabling some not. And a very high proportion of abnormal personalities, continuously abnormal in some way. Not psychopaths, there were only three psychopaths. But I can't get it published. The criticisms were so sharp I asked Raymond Levy to read it in case it showed senile deterioration.

BB How did you select the sample?

FP I chose from the names of famous writers or novelists, and because a modern or fairly modern biography was available. I assumed that biographers don't choose their subjects because they are interested in their neuroses, except very occasionally, but in the artist's work, and life and how that all hangs together. I can't imagine that they just picked up all the ones that were abnormal. It is, however, not a random sample and publication has been declined because of that.

I am now doing scientists; I have got about 25 so far, and I hope to get 50 . I have selected them on the same principles as the writers, being world famous and with an available biography. There are fewer biographies and I cannot always have recent ones. I have some where the biographies were written in perhaps the 1870 s. Even so a lot of material is very useful. So far one scientist is psychotic, and a few are neurotic, one or two severe, but far, far less than the authors, and there certainly are fewer abnormal personalities.

BB I suppose the Royal Society's Fellows' obituaries would provide a sampling frame?

FP Yes, maybe. But I have chosen to have world famous scientists, because my authors were chosen as world famous. So I have to have people of international repute, Einstein, Bohr, Rutherford, Faraday, Darwin, Pasteur.

BB Sounds an absorbing hobby?

FP I have found evidence of a lot of minor psychiatric disturbance, especially amongst the authors. Quite a lot of family histories. of suicides, more than you would expect. With many of the minor psychiatric disorders, it is difficult to be sure that they are not cyclothymia. I mean the tendency to depression of a mild sort. Not every neurotic breakdown is cyclothymia although one suspects it is very often.

BB It's the euphoria that's the interest, isn't it?

FP There were very few who were euphoric. They have drive and that's why they are geniuses. All these geniuses have things in common with world famous people. They are tremendously engaging, they are going at it and not looking right or left, and persevering when other people would have given up. Tremendously industrious you see.

BB Industrious on the right things?

FP Not all were successful. A lot have also done things which didn't produce.

BB Lord Rutherford was pretty normal?

FP He smoked all the time to keep himself calm because he was so tense and nervous. But he didn't have breakdowns, well nothing that you could say. But then you have to be careful. When he was first in London on his own and did not know what to do, he had a lot of migraine, a lot of aches and pains. I don't call that a psychiatric disturbance. I am cautious and conservative. These are some of the selfinflicted tribulations of retirement. 